\title{
Case Report \\ Successful Spontaneous Pregnancy after Treatment for Ewing Sarcoma including Sacrectomy
}

\author{
T. Hockertz and M. Velickovic $\mathbb{D}$ \\ Department of Orthopedic Surgery, Sports Traumatology and Trauma Surgery, Städtisches Klinikum Wolfenbüttel, \\ Alter Weg 80, 38302 Wolfenbüttel, Germany \\ Correspondence should be addressed to M. Velickovic; mirko.velickovic@gmx.de
}

Received 13 September 2017; Accepted 25 March 2018; Published 30 April 2018

Academic Editor: Seung-Yup Ku

Copyright (C) 2018 T. Hockertz and M. Velickovic. This is an open access article distributed under the Creative Commons Attribution License, which permits unrestricted use, distribution, and reproduction in any medium, provided the original work is properly cited.

Ewing sarcomas are highly malignant bone tumors and usually occur in childhood. Radiation therapy, chemotherapy, and surgical methods increase the survival rate of the affected patient, but infertility and reduced reproductive capacity are common late effects of pediatric cancer treatment.

\section{Introduction}

We report on the pregnancy of a patient with Ewing sarcoma treated at the age of 18 with chemo- and radiotherapy as well as total sacrectomy. In the course of time, a "neosacrum" developed and the patient gave birth to a boy at the age of 29. The course of pregnancy was uneventful. This was the second pregnancy of this patient. At the time of pregnancy, the patient was 29 years old.

\section{Case Presentation}

The patient was 18 years old at the time Ewing sarcoma of the sacrum was diagnosed. At the time when the patient consulted for the first time a doctor, she was already suffering from progressive pain in the lumbosacral region radiating into both legs with saddle block anesthesia, foot flexor paresis, and episodes of bladder and stool incontinence for four months. An initial MRI of the lower spine suggested a tethered cord syndrome and the patient was transferred and operated on in a neurosurgical clinic, but the patient did not benefit from the surgery. In an additional MRI of the pelvis, a large tumor was found. The tumor was partly intra-, partly extraosseous and involved the entire right sacrum wing and extended into the small pelvis and the dorsal pelvic soft parts. The histopathological examination of the sample biopsy confirmed Ewing sarcoma. Staging showed no evidence of metastasis of the tumor. The stage was documented with T3 N0 M0. We treated the patient with a combination of neoadjuvant chemotherapy, radiation therapy, and sacrectomy. In the first preoperative phase, the patient received 3-day blocks of polychemotherapy consisting of vincristine, etoposide, doxorubicin, and ifosfamide. This was performed preoperatively six times at intervals of 3 weeks. The tumor showed a marked reduction in size from $9 \mathrm{~cm} \times 6.5 \mathrm{~cm} \times 12 \mathrm{~cm}$ before the start of the therapy and $8 \mathrm{~cm} \times 5,5 \mathrm{~cm} \times 10,5 \mathrm{~cm}$ after 6 chemotherapy blocks (data in each case in width $\times$ depth $\times$ height). Total sacrectomy followed. In a first step, the position of the lumbar spine was secured with a lumbopelvic fixation from the ileum to the third lumbar vertebral body. The tumor could not be removed en bloc, so we performed an intralesional tumor resection. Before complete dissection of the sacrum was done, we placed an angular-stable ilioiliacal LCP plate sacrum in order to ensure an anatomical position of the pelvis (Figure 1). Postoperatively, we continued chemotherapy as well as radiation therapy due to the intralesional tumor resection. The radiation dose was $45 \mathrm{~Gy}$. The follow-up period was 12 years. The radiological follow-up examinations over the course of time documented a nearly complete sacral osteoneogenesis including the neuroforamina with a stable fusion of the new sacrum with the posterior pelvic ring (Figures 2 and 3). The clinical outcome was very good, and the gait was almost normal; no crutches were needed anymore. Neurologically, an incomplete paraplegia remained, with preserved motor function and sensitivity below the spinal cord injury site L5/S1 with a clinically nonrelevant peroneal paresis on the right, 


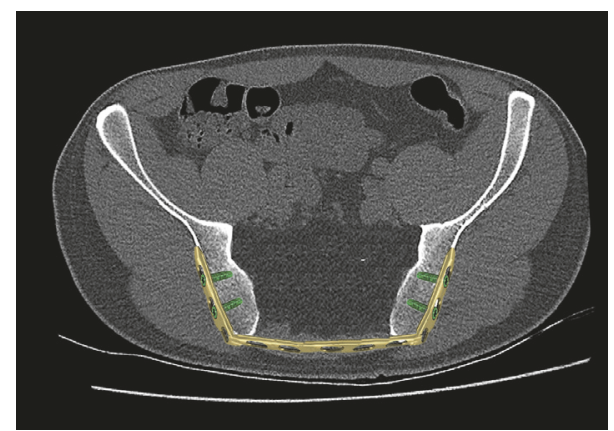

FIGURE 1: Schematic representation of the sacrectomy.

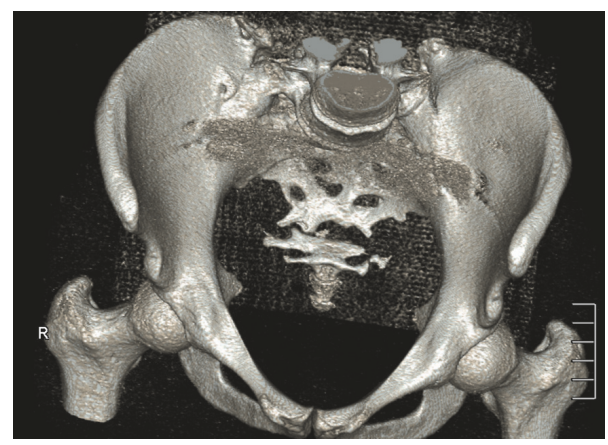

FIGURE 2: CT reconstruction of the pelvis showing the "neosacrum."

discrete paresthesia on the right lateral thigh and distal lower limbs, and a neurogenic bladder dysfunction.

\section{Pregnancy}

Contraception was done with birth control pills. The patient wanted to conceive so this medication was stopped. Three months later, the patient was pregnant at the age of 28 but lost the child in the 8th week of pregnancy. Curettage was necessary. The second pregnancy at the age of 29 was successful and she gave birth to a boy of $3460 \mathrm{~g}$ and $50 \mathrm{~cm}$ through a cesarean section at the 37 weeks' gestation by a community obstetrician. There were no birth complications (Figure 5).

\section{Discussion}

Ewing sarcoma is a highly malignant bone tumor which rapidly metastasizes at an early stage. Treatment options include radiation, chemotherapy, and operation. The combination of chemotherapy with both surgery and radiotherapy increases the survival rate by $15-20 \%$ as compared to chemotherapy with either local therapy alone [1,2]. Prognosis has been improved in recent years. In the 1960s, the 2-year survival rate was only $21 \%$. Due to modern treatments, longterm survival up to $70 \%$ to $80 \%$ can be reached among patients without metastases $[3,4]$. The aim of treatment is to cure the patient with the least cost in terms of long-term morbidity.

A major fear among female survivors is the long-term effects of cancer therapy especially infertility. Family planning is for most people an essential part of life quality. In general, cancer survivors are less likely to become pregnant when compared to their siblings [5-7].
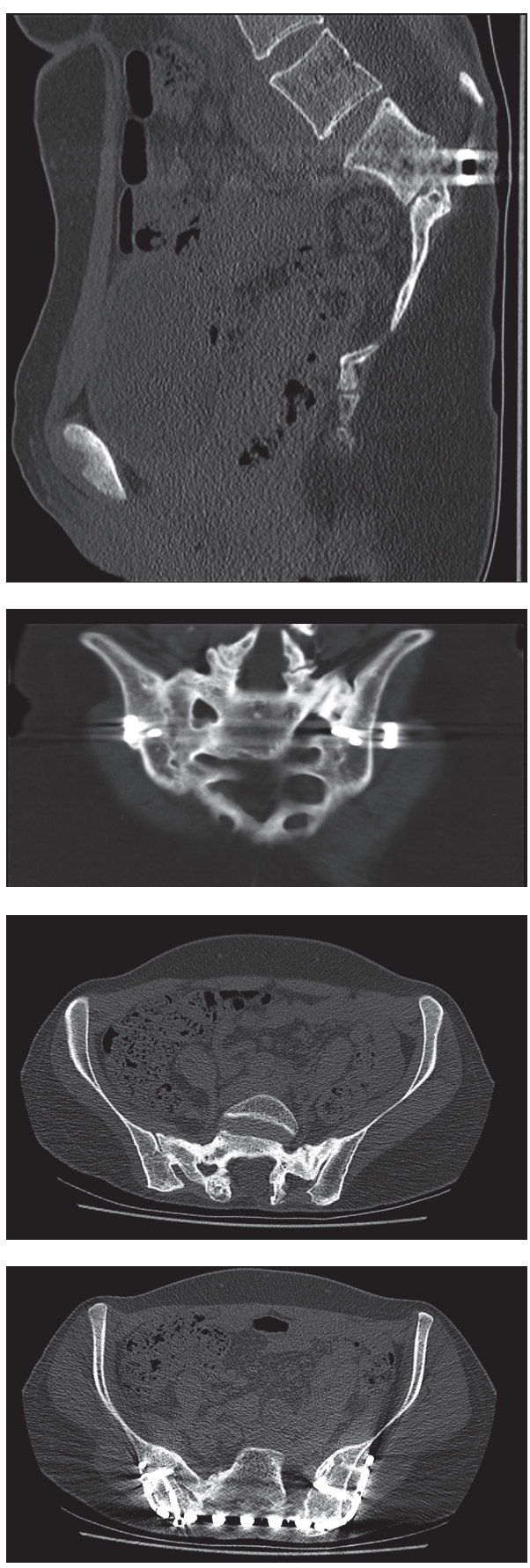

FIGURE 3: Selection of CT slices of the pelvis (CT and X-ray of the lower spine and pelvis were done in another hospital in 2015 due to lower back pain).

Ewing sarcoma occurs mainly in childhood. Strategies for preserving fertility are limited and should be planned before starting tumor therapy and discussed with the patient and family. However, this is often not possible due to the urge to start with the therapy. In general, we recommend an interdisciplinary team including a gynecologist in order to choose the best way to preserve fertility. Even in prepubertal girls, the physician should keep the possible wish to have children later on in mind. In our case, the patient was 18 
years old when Ewing's sarcoma was diagnosed. There was no gynecologist involved and no pretreatment to preserve fertility was done.

According to Lee et al., there are several well established methods to preserve fertility, including gonadal shielding during radiotherapy, trachelectomy, and ovarian transposition. Methods like embryo cryopreservation are only useful in established stable partnership which is unlikely at the patient's age. Other methods like oocyte cryopreservation, ovarian cryopreservation and transplantation, and ovarian suppression with GnRH analogs or antagonists are experimental. But Lee et al. also highlighted that ovarian tissue cryopreservation and reimplantation is a main option to preserve fertility of cancer patients who need an immediate start of the cancer treatment. For patients in the prepubertal age, freezing is the only option to preserve fertility [8]. Up to now, a total of 17 babies from 12 patients have been born worldwide from ovarian tissue cryopreservation and reimplantation [8-10]. Three of them suffered from Ewing's sarcoma.

Treatment with multiagent chemotherapy, radiotherapy, and surgical procedures such as sacrectomy is associated with significant late effects and reduces the chance of pregnancy [11].

Radiation therapy leads to decreased fertility depending on the site irradiated. Ewing's sarcoma most commonly affects the femur and the pelvis in $20 \%$ of cases, so the female reproductive system is often affected. The younger the patient at the time of radiation, the greater the probability of infertility. The risk of pregnancy complications such as miscarriage, preterm delivery, and perinatal death is higher. There is also a higher risk of low birth weight less than $2500 \mathrm{~g}$ in infants born to patients treated with pelvic irradiation [12]. There is no known radiation dose threshold for uterine damage, but abdominal radiation with 20-30 Gy in childhood already leads to ovarian failure [13]. According to Teh et al., no successful pregnancy been reported after a direct radiation dose (>45 Gy) to the whole pelvis [14]. Our patient received a radiation dose of $45 \mathrm{~Gy}$ with no protective measures like ovarian transposition.

Haerr and Pratt recommend early chemotherapy in the course of many malignant sarcomas, despite pregnancy, to prevent the occurrence of metastases [15]. It is known that busulfan and high doses of lomustine are significantly associated with reduced pregnancy in female survivors of childhood cancer not exposed to pelvic or cranial radiotherapy. According to the same authors, chemotherapy-specific effects on pregnancy were generally few in patients without radiotherapy to the pelvis [16].

There is only one case in the literature which is similar to our case.

Kakogawa et al. reported a case of successful pregnancy in a patient who underwent sacrectomy combined with multiagent chemotherapy and radiotherapy for Ewing's sarcoma. The patient was diagnosed with Ewing's sarcoma of the sacrum at the age of 16 . But in this case, pretreatment in order to protect the reproductive system was carried out, the ovaries were transposed, the uterus was shielded, and a gonadotropin-releasing hormone agonist was used during treatment to protect the ovarian function. The patient
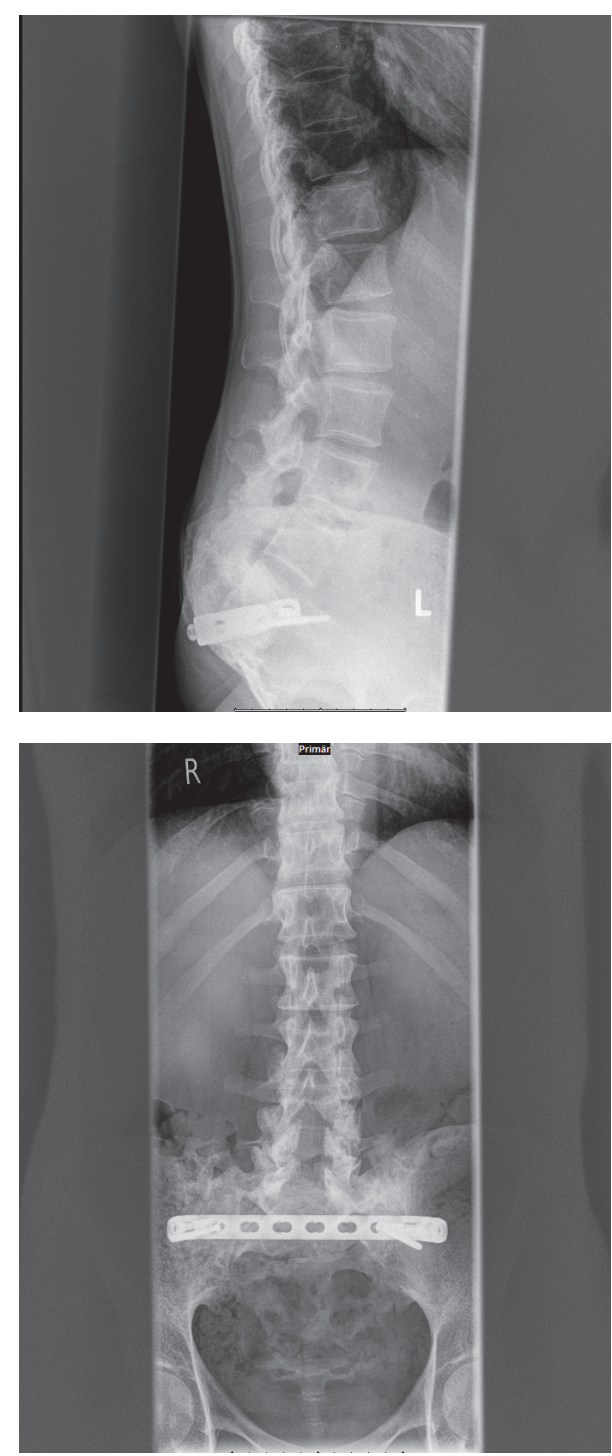

FIGURE 4: X-ray of the lower spine with ilioiliacal plate.

spontaneously conceived at the age of 27 [4, 17]. On the other hand, a spontaneous return of ovarian function and conception years after gonadal chemotherapy with evidence of ovarian failure is possible [18].

At the time the patient arrived at our hospital, she already suffered from severe neurologic symptoms. Due to the urgency to start with the therapy, no precautions were taken to maintain fertility.

This is the 6th reported case of pregnancy in a patient with Ewing's sarcoma [4,19-21]. All women became naturally pregnant. The pregnancy course was in 4 cases uneventful; in one case only, an inadequate descent of the fetal head occurred due to pelvic distortion. In 3 cases, a caesarian section was done. In the other cases, the way of delivery is unknown. We also recommend a caesarian section. Biomechanically, the ilioiliacal pelvic plate acts as an internal fixator which prevents widening of the posterior pelvic ring at birth (Figure 4). In the case of a vaginal birth, the baby could be stuck in the birth canal or the pelvic ring may burst open. 

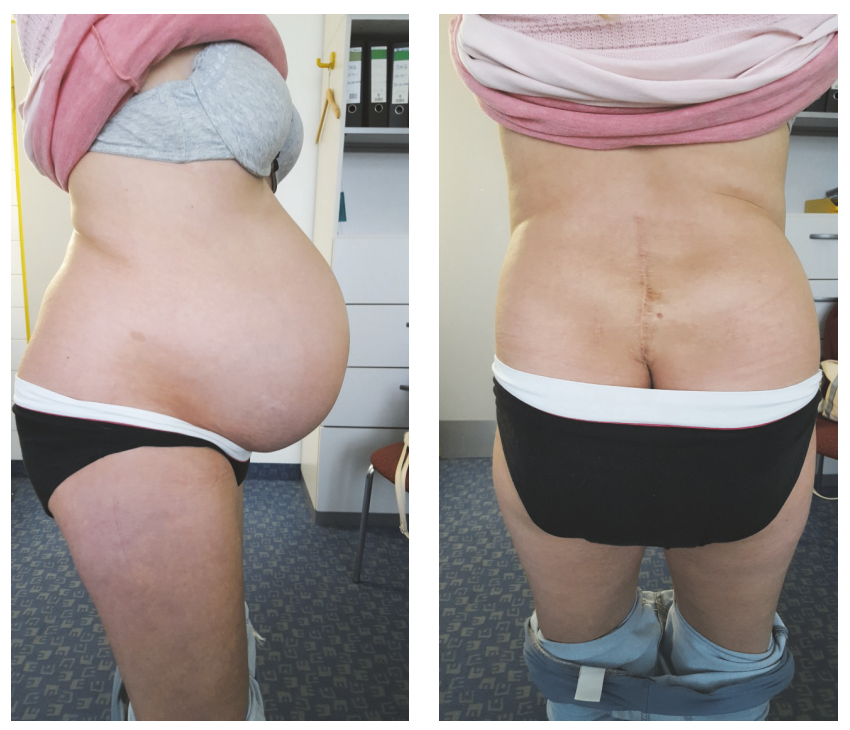

FIGURE 5

Both would put the mother and the child in unnecessary danger. Neurologically, an incomplete paraplegia remained, with preserved motor function and sensitivity below the spinal cord injury site L5/S1 with a clinically nonrelevant peroneal paresis on the right, discrete paresthesia on the right lateral thigh and distal lower limbs, and a neurogenic bladder dysfunction. Neurological deficits are not an absolute indication for cesarean delivery but caesarian section is recommended to reduce the risk for the baby.

Successful and uneventful pregnancy after sacrectomy combined with chemotherapy and radiotherapy can be achieved even without pretreatment for fertility preservation.

\section{Conflicts of Interest}

The authors declare that there are no conflicts of interest regarding the publication of this paper.

\section{References}

[1] "AWMF Interdisziplinäre Leitlinie der Deutschen Krebsgesellschaft und der Gesellschaft für Pädiatrischen Onkologie und Hämatologie, Ewing-Sarkome und PNET des Kindes- und Jugendalters," http://www.awmf.org/leitlinien/detail/ll/025-006 .html.

[2] A. Schuck, S. Ahrens, M. Paulussen et al., "Local therapy in localized ewing tumors: results of 1058 patients treated in the CESS 81, CESS 86, and EICESS 92 trials," International Journal of Radiation Oncology, Biology, Physics, vol. 55, no. 1, pp. 168-177, 2003.

[3] U. Dirksen and H. Jürgens, "Approaching Ewing sarcoma," Future Oncology, vol. 6, no. 7, pp. 1155-1162, 2010.

[4] J. Kakogawa, T. Nako, K. Kawamura et al., "Successful Pregnancy After Sacrectomy Combined With Chemotherapy and Radiation for Ewing Sarcoma: Case Report and Literature Review," Journal of Pediatric \& Adolescent Gynecology, vol. 28, no. 3, pp. e79-e81, 2015.
[5] H. Magelssen, K. K. Melve, R. Skjærven, and S. D. Fosså, "Parenthood probability and pregnancy outcome in patients with a cancer diagnosis during adolescence and young adulthood," Human Reproduction, vol. 23, no. 1, pp. 178-186, 2008.

[6] J. Y. Wo and A. N. Viswanathan, "Impact of radiotherapy on fertility, pregnancy, and neonatal outcomes in female cancer patients," International Journal of Radiation Oncology, Biology, Physics, vol. 73, no. 5, pp. 1304-1312, 2009.

[7] D. M. Green, T. Kawashima, M. Stovall et al., "Fertility of female survivors of childhood cancer: A report from the childhood cancer survivor study," Journal of Clinical Oncology, vol. 27, no. 16, pp. 2677-2685, 2009.

[8] S. Lee, J. Y. Song, S. Y. Ku, S. H. Kim, and T. Kim, "Fertility preservation in women with cancer," Clinical and Experimental Reproductive Medicine, vol. 39, no. 2, p. 46, 2012.

[9] R. Grundy, R. G. Gosden, M. Hewitt et al., "Fertility preservation for children treated for cancer (1): Scientific advances and research dilemmas," Archives of Disease in Childhood, vol. 84, no. 4, pp. 355-359, 2001.

[10] S. J. Silber, "Ovary cryopreservation and transplantation for fertility preservation," Molecular Human Reproduction, vol. 18, no. 2, Article ID gar082, pp. 59-67, 2012.

[11] L. E. Bath, W. Hamish, B. Wallace, and H. O. D. Critchley, "Late effects of the treatment of childhood cancer on the female reproductive system and the potential for fertility preservation," BJOG: An International Journal of Obstetrics \& Gynaecology, vol. 109, no. 2, pp. 107-114, 2002.

[12] D. M. Green, C. A. Sklar, J. D. Boice Jr. et al., "Ovarian failure and reproductive outcomes after childhood cancer treatment: results from the childhood cancer survivor study," Journal of Clinical Oncology, vol. 27, no. 14, pp. 2374-2381, 2009.

[13] W. H. B. Wallace, S. M. Shalet, E. C. Crowne, P. H. Morris-Jones, and H. R. Gattamaneni, "Ovarian failure following abdominal irradiation in childhood: natural history and prognosis," Clinical Oncology, vol. 1, no. 2, pp. 75-79, 1989.

[14] W. T. Teh, C. Stern, S. Chander, and M. Hickey, "The impact of uterine radiation on subsequent fertility and pregnancy outcomes," BioMed Research International, vol. 2014, Article ID 482968, 2014.

[15] R. W. Haerr and A. T. Pratt, "Multiagent chemotherapy for sarcoma diagnosed during pregnancy," Cancer, vol. 56, no. 5, pp. 1028-1033, 1985.

[16] E. J. Chow, K. L. Stratton, W. M. Leisenring et al., "Pregnancy after chemotherapy in male and female survivors of childhood cancer treated between 1970 and 1999: A report from the Childhood Cancer Survivor Study cohort," The Lancet Oncology, vol. 17, no. 5, pp. 567-576, 2016.

[17] P. Hürmüz, D. Sebag-Montefiore, P. Byrne, and R. Cooper, "Successful spontaneous pregnancy after pelvic chemoradiotherapy for anal cancer," Clinical Oncology, vol. 24, no. 6, pp. 452-458, 2012.

[18] J. Nasir, C. Walton, S. W. Lindow, and E. A. Masson, "Spontaneous recovery of chemotherapy-induced primary ovarian failure: Implications for management," Clinical Endocrinology, vol. 46, no. 2, pp. 217-219, 1997.

[19] L. E. Bath, G. Tydeman, H. O. D. Critchley, R. A. Anderson, D. T. Baird, and W. H. B. Wallace, "Spontaneous conception in a young woman who had ovarian cortical tissue cryopreserved before chemotherapy and radiotherapy for a Ewing's sarcoma of the pelvis: case report," Human Reproduction, vol. 19, no. 11, pp. 2569-2572, 2004. 
[20] I. G. Chihara, H. Osada, Y. Iitsuka, K. Masuda, and S. Sekiya, "Pregnancy after limb-sparing hemipelvectomy for Ewing's sarcoma: A case report and review of the literature," Gynecologic and Obstetric Investigation, vol. 56, no. 4, pp. 218-220, 2003.

[21] N. Sharon, Y. Neumann, G. Kenet, J. Schachter, G. Rechavi, and A. Toren, "Successful pregnancy after high-dose cyclophosphamide and ifosfamide treatment in two postpubertal women," Pediatric Hematology and Oncology, vol. 18, no. 4, pp. 247-252, 2001. 


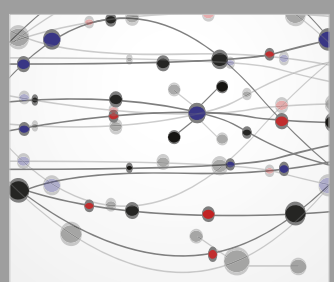

The Scientific World Journal
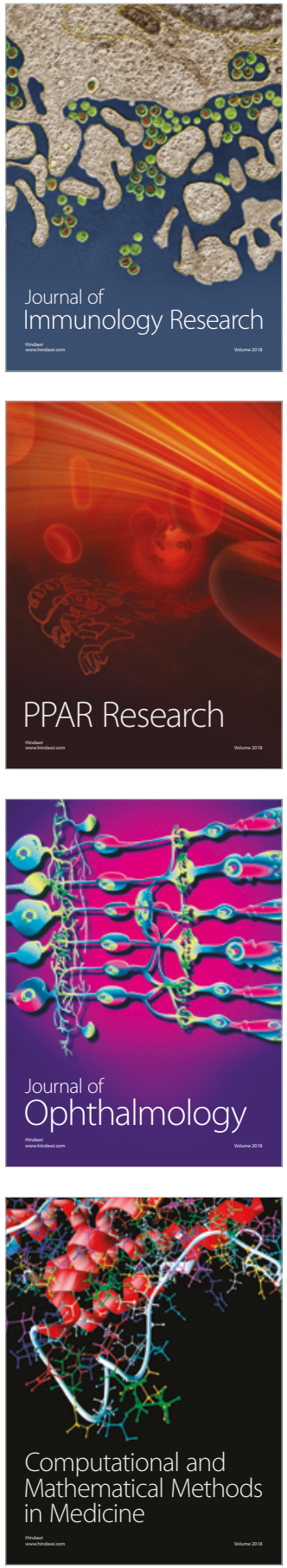

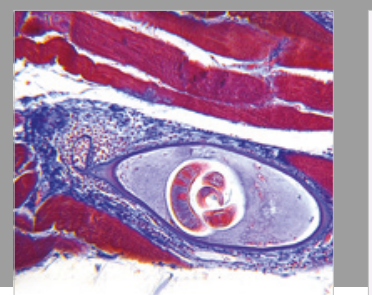

Gastroenterology Research and Practice

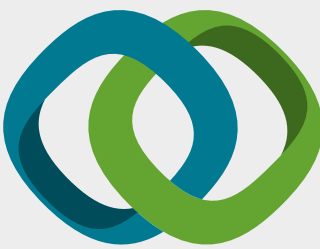

\section{Hindawi}

Submit your manuscripts at

www.hindawi.com
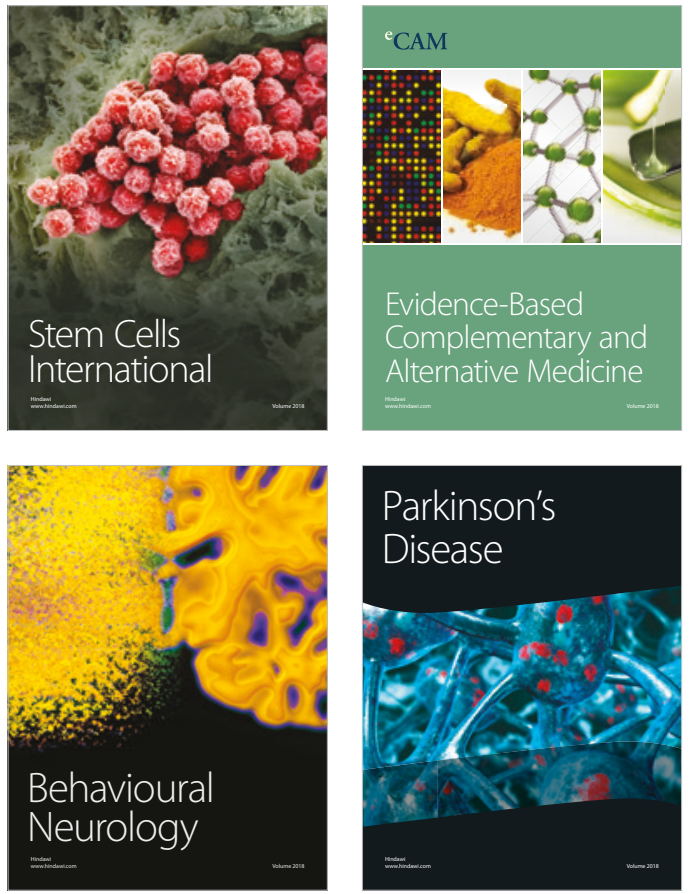

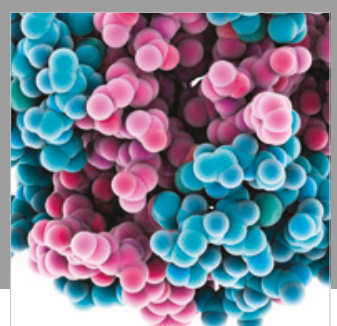

ournal of

Diabetes Research

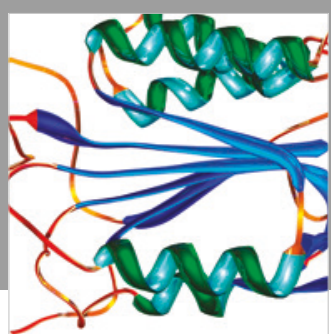

Disease Markers
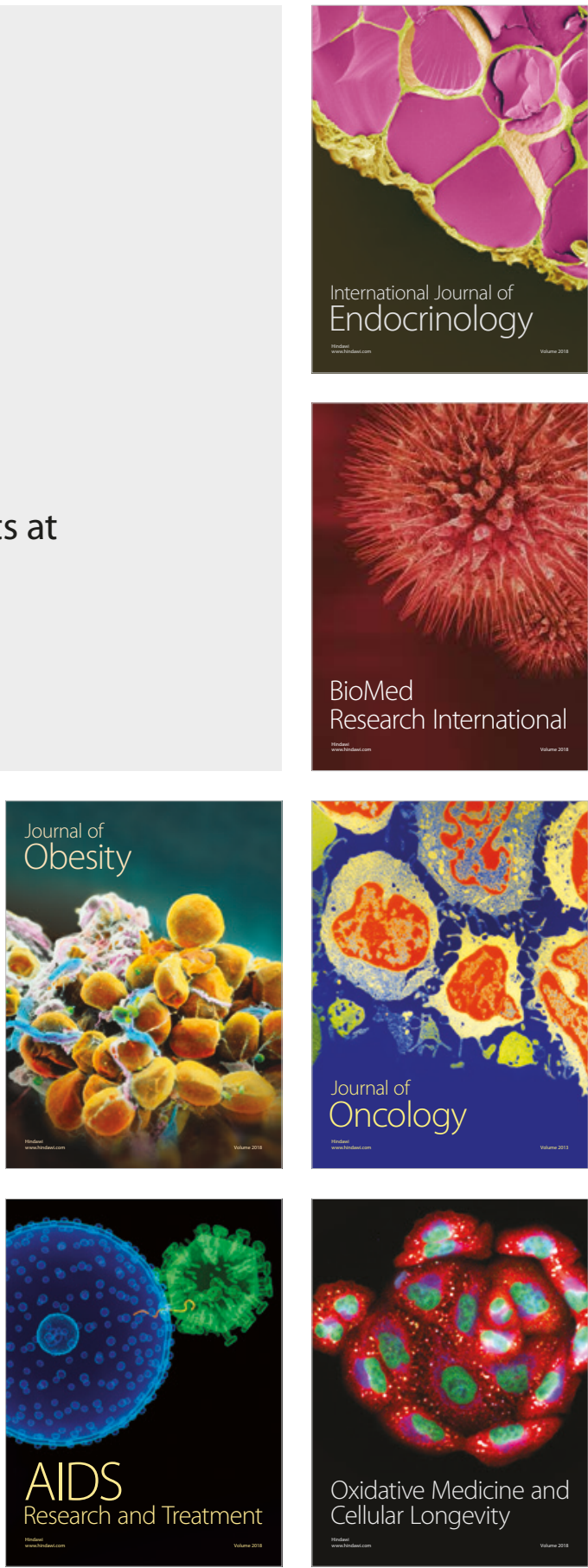